\title{
EL QUIJOTE, UNA LECTURA FRONTERIZA
}

\begin{abstract}
Juan Villoro
En este ensayo se aborda la obra capital de Cervantes como "road novel" e incesante cruce de fronteras. Estructurada a partir de los desplazamientos, la ficción cervantina funda simultáneamente la novela moderna y la metanovela, la discusión de la literatura desde su propio territorio. Uno de los desafíos centrales de la trama es cómo se escribe y cómo se lee un libro. Cervantes violenta los límites entre lo real y lo fantástico y explora una arriesgada frontera psicológica, la que separa la sensatez de la melancolía y del delirio: figura limítrofe, don Quijote está siempre entre dos realidades. Territorio de la "escritura desatada", donde los indocumentados adquieren voluntaria ciudadanía, la novela depende de intensas mezclas culturales, contrabandos, encrucijadas y transgresiones, en suma, de la inescapable noción de frontera.
\end{abstract}

JuAn Villoro. Escritor mexicano. Nació en el Distrito Federal el 24 de septiembre de 1956. Autor, entre muchas otras obras, de los cuentos La casa pierde (1999, Premio Xavier Villaurrutia), El mariscal de campo (1978), La noche navegable (1980), El cielo inferior (1984); la novela El testigo (Premio Herralde 2004); los ensayos Efectos personales (2000, Premio Mazatlán) y Los once de la tribu (1995); de las crónicas El tiempo transcurrido (1986) y los relatos infantiles Las golosinas secretas (1985) y Baterista numeroso (1997). Ha colaborado en las revistas Cambio, Gaceta del Fondo de Cultura Económica, Universidad de México, Crisis, La Orquesta, La Palabra y el Hombre, Nexos, Vuelta, Siempre!, Proceso y Pauta, de la cual fue jefe de redacción, y del suplemento "Revista de Libros", de El Mercurio de Santiago. Fue agregado cultural en la Embajada de México en Berlín (1981-1984) y director del suplemento La Jornada Semanal (1995 a 1998). En 1988 fue distinguido con el Premio Cuauhtémoc de Traducción.

Estudios Públicos, 100 (primavera 2005). 


\section{Desmesurada vida de lector}

工 a suerte de una literatura depende de la forma en que es leída. Sujetos a las consideraciones de la época, los libros modifican su contenido sin cambiar de forma. El exagerado Pierre Menard escribe otro Quijote con idénticas palabras.

Italo Calvino encontró una sencilla definición de clásico: un libro que no cesa y "nunca termina de decir lo que tiene que decir". Sin embargo, habría que precisar, con Borges, que la sostenida irradiación de esas páginas depende de manera fundamental de sus testigos. El tema, por supuesto, proviene del Quijote y constituye su núcleo inventivo, la estrella polar de su universo. Cervantes concibe la aventura de un lector radical, incapaz de distinguir la realidad de la fabulación. La lectura patenta el carácter con el que comparecerá en un escenario que es, precisamente, la construcción de un libro.

En el primer tramo de la novela, el forajido Ginés de Pasamonte alardea de que se escriba un libro sobre sus peripecias. "Y ¿está acabado?”, le pregunta el Caballero de la Triste Figura. “¿Cómo puede estar acabado, si aún no está acabada mi vida?", responde Ginés. Cervantes muestra a un personaje cuya vida se escribe a medida que sucede, y amplía el juego de espejos: don Quijote discute lo que ya se escribió de él y actúa para seguir siendo escrito.

Nada sabemos de la infancia o la juventud del protagonista. Llega a nosotros como las figuras míticas, con sus atributos finales. Poco importa lo que le pasó antes porque no era así. Emerge transfigurado por su inmersión en la lectura: no distingue dónde terminan los libros y dónde comienzan las áridas tierras de la Mancha.

Una noción de traslado esencial a la imaginación de Cervantes es la que se refiere a la recepción del texto. Los mensajes dependen menos de su configuración que de la forma en que son recibidos. El arte moderno se funda en este desplazamiento en la valoración de la obra. La belleza y sus efectos no son atributos inmanentes de las cosas (como quería el ideal pitagórico); dependen de una apropiación creativa de lo real. En sí mismo, el tema puede ser un objeto desastrado, equívoco y aun repelente. El fulgor negro del arte español (del Lazarillo a Goya y al esperpentismo) no se explica sin este esencial viraje en la percepción estética.

Don Quijote ve el mundo como lo ha leído y así subraya que la literatura se determina por su acto final, la interpretación. Por supuesto, está loco de atar y su locura es el motor de la historia; sin embargo, al centro de 
ese ciclón de disparates anida un remanso de cordura. La novela despliega toda clase de peripecias provocadas por alucinaciones y por un falso sentido de la consecuencia, pero también las "discretas razones" a las que sólo se llega por vía extrema o largo rodeo. La sensatez a contrapelo del Quijote le permite argumentar con buen juicio sobre lo que ha malinterpretado. ¿Hay mejor ejemplo del valor múltiple del texto, la sobreinterpretación, los misreadings, la lectura paranoica y la teoría de la recepción que las maneras en que el perturbado caballero combina el rigor y el delirio para leer el mundo?

Desde el Prólogo, Cervantes se define como intermediario de materiales ajenos. Sólo en parte se hace responsable de la obra: se define como su padrastro, notable concepción de la autoría. En la cultura popular, el padrastro suele encarnar los defectos de la autoridad sin sus virtudes compensatorias. Una figura limítrofe, a medio camino entre el deber y el afecto. Así es el autor del Quijote; se ha esforzado para conseguir las páginas que pueden leerse en el libro, pero no le corresponden los méritos de la invención. Estamos, pues, ante una obra que guarda autonomía respecto al escritor bajo cuyo nombre se ampara. No se trata del recurso del "manuscrito hallado" ni del anónimo sino de algo más raro, un resultado en parte ajeno y en parte propio, un hijastro.

Cervantes se propone como lector inaugural de la obra: ensambla lo que encuentra. Pero no es indiferente a los hallazgos: también es el primer comentarista del relato. En el párrafo inicial informa que el personaje ya ha sido narrado, incluso con discrepancia ("hay alguna diferencia en los autores que deste caso escriben"); un sustrato legendario llega a nosotros de nueva cuenta. En el capítulo IX sobreviene un giro: la versión presente del texto ha sido traducida del árabe; su autor es Cide Hamete Benengeli. Así se establece otra mediación. El "autor" (Cervantes) recopila, arma y, puesto que no sabe árabe, consigue traductores para la obra.

Esto aumenta la deliberada impureza del texto. La historia proviene de un traslado de idiomas. Cervantes, que luchó en Lepanto y cayó preso en Argel, hace que el original provenga de una cultura enemiga. Traducirlo implica cruzar a medias una frontera; es mucho lo que se pierde en el camino. A propósito de las traducciones, comenta don Quijote: "Me parece que el traducir de una lengua en otra, como no sea de las reinas de las lenguas, griega y latina, es como quien mira los tapices flamencos por el revés, que aunque se veen las figuras, son llenas de hilos que las escurecen". Cervantes escoge una lengua extranjera y plebeya para contar desde el reverso del tapiz. Corresponde a la lectura transformar el "largo y espacioso campo" de la novela en un dibujo nítido. 
El Quijote trata, ante todo, de cómo se escribe un libro.

La trama se estructura a medida que se lee; si unas páginas se pierden (como en el célebre episodio que deja al vizcaíno con la espada suspendida en el aire), habrá que encontrarlas para que la lectura continúe. En la segunda parte, cuando la primera ya goza de reputación editorial y circula la versión pirata de Avellaneda, los personajes comentan su pasado como un libro y enfrentan el porvenir como un capítulo inédito. Vida y texto son para ellos idénticos.

Francisco Rico, que ha fijado los criterios modernos decisivos de aproximación a la obra, comenta que en la segunda parte don Quijote y Sancho encuentran un mundo que ya es quijotesco: otros personajes conocen su reputación y la ponen a prueba. En diez años (de la aparición del primer volumen al segundo) la aventura ha ganado celebridad. Don Quijote es él más su leyenda. “En 1605 se le presenta como 'famoso' sin serlo; en 1615 lo era como pocos", escribe Rico en el Prólogo a la edición del Quijote que preparó para la Junta de Comunidades de Castilla-La Mancha. Los episodios de Clavileño y la Ínsula Barataria demuestran la disposición de personajes nada quijotescos a urdir una celada típicamente quijotesca. Que el mundo se parezca tanto a sus fantasías desconcierta al protagonista: "frente a las firmezas de otros tiempos, ha comenzado a no saber" (Rico). Don Quijote se confunde por el triunfo de su estilo y la excesiva aceptación de sus intérpretes.

Puesto que, de acuerdo con el juego de suplantaciones, se desconoce el original de la obra, toda lectura es tentativa. Esta vía indirecta al relato depende de una lengua que mezcla lo culto y lo popular, retórica y oralidad, el romance y los libros de pordiosería, y que admite la posibilidad de ser errónea.

Cervantes opera desde la inseguridad de quien no es un autor único y definitivo; se sirve de un idioma que sabe débil. Esto le permite absorber con mayor libertad voces ajenas, pues no depende de un código asentado. A propósito de Kafka, Deleuze y Guattari hablaron de lengua menor para su elección del alemán en la comunidad judía de Praga, en vez del checo o del yidish, idiomas que llegaban a él con una carga cultural más rígida y definida. Cervantes escribe en la lengua del imperio y en su siglo de esplendor, pero simula perseguir una historia perdida, escrita en una lengua ajena; los árabes, recuerda en su calidad de intermediario, son muy mentirosos: ninguna reticencia es poca con quienes son "tan nuestros enemigos". La noción de frontera y contrabando resulta decisiva en la concepción de Cide Hamete Benengeli, enfrentado contra el castellano. Si Vargas Llosa escribió una 
"carta de batalla" para la gesta de Tirant lo Blanc, el Quijote reclama en su migrante andadura un "permiso de residencia" para la novedad de su estilo, disfrazado de extranjería.

Jean Canavaggio, biógrafo de Cervantes, pone especial cuidado en describir el rico repertorio cultural que le deparó su vida movediza. De joven, respiró el Renacimiento en Italia, se enroló durante cuatro años en la milicia, cayó preso en Argel por cinco años, regresó a la península Ibérica para llevar una errabunda existencia de recaudador de impuestos, volvió a ser preso, esta vez en Sevilla, donde se concentraba la picaresca más variopinta del Siglo de Oro.

Los comentarios de Cervantes sobre otras culturas son de una tolerancia inusual en su época. Conviene recordar que el primer Índice de la Inquisición fue promulgado en 1547, año del nacimiento de Cervantes. La historia del idioma vive en ese tiempo su mayor expansión creativa y su etapa más restrictiva. Si algo se puede decir de la personalidad del novelista, que contagia a buena parte de sus personajes, es que encaró la fatalidad con idénticas dosis de resignación, interés y humor crítico. Este talante se aplica también a las culturas desconocidas y lo singulariza en un tiempo poco amigo de la otredad. Cervantes leyó en italiano, luchó cuerpo a cuerpo con los turcos, trabó íntimas amistades en Argel, conoció a toda clase de soldados, prisioneros, pobres diablos endeudados. Después de una pausa de veinte años, regresó a las letras con una obra que recogía imprevistas influencias: un presunto libro árabe, parodia del género de la caballería, donde comparecían el poema, la procacidad carcelaria e historias que nada tenían que ver con eso.

Como suele ocurrir en el celoso ámbito de las letras, quien mejor entendió la fuerza renovadora de este relato mestizo fue un competidor. En una carta escrita antes de la publicación del Quijote, Lope de Vega previene acerca de su perniciosa aparición. La época lo recibió como un espectáculo de ingenios y Cervantes murió con la certeza de haber entretenido a sus lectores. Como ha explicado Rico, durante siglos el Quijote fue un divertimento en español y un clásico en inglés, francés y alemán. Sólo hasta el siglo XVIII también ganó el rango de pieza definitiva en español. Es posible que la tardanza en aceptar la profundidad del libro se debiera en parte a que en forma deliberada pactaba con otras culturas y tradiciones; desde su origen tenía algo "extranjero", bastardo: renovaba lo propio con recursos ajenos y aun "enemigos". Al encomiar la "escritura desatada", Cervantes fundaba la novela moderna como tierra de indocumentados. 


\section{La invención del contexto}

Llama la atención el pasaje seleccionado por Borges para demostrar que el Quijote calcado letra a letra por Pierre Menard es el mismo y es otro del escrito por Cervantes. En el capítulo VIII del Ingenioso hidalgo..., la acción se interrumpe porque se pierde el manuscrito y el vizcaíno queda con la espada en alto frente a don Quijote. En el siguiente episodio, Cervantes explica en primera persona los esfuerzos que se tomó para hallar las páginas faltantes y aclara que siempre le ha gustado leer, "aunque sean los papeles rotos de las calles". Cuando encuentra el pasaje que falta, reflexiona acerca de su veracidad y la impresión que de él tendrá el lector. ¿Cómo calibrar lo que proviene de un mentiroso que trabaja en árabe? Es justo en ese punto donde Borges inserta a un tercer "autor", el francés Pierre Menard. El copista transcribe: "la verdad, cuya madre es la historia, émula del tiempo, depósito de las acciones, testigo de lo pasado, ejemplo y aviso de lo presente, advertencia de lo porvenir". Borges ahonda la ironía cervantina de hablar en nombre de una verdad que no se puede cumplir. Cervantes y Borges responden al mismo impulso: lo que define la lógica del texto es la manera en que lo leemos. Los extranjeros Cide Hamete Benengeli y Pierre Menard reciben carta de naturalización por el contexto en que son leídos.

En otra referencia al ilocalizable autor del Quijote, Cervantes lo define como "sabio arábigo y manchego", el origen se torna mixto: un forastero aclimatado en Iberia. Su identidad híbrida ampara el relato que tanto se beneficia con las mezclas.

Pero Cide no es el único autor del texto; actualiza relatos precedentes. José Balza ha llamado la atención sobre un hecho recurrente en el Quijote: la referencia a cuando la obra no estaba escrita. "Aunque hasta ese momento la humanidad desconozca obras de ficción como el propio Quijote, el hecho de que haya habido otros narradores, otros autores capaces de crear un libro como él, establece antecedentes imaginarios para que éste sea posible. Los anónimos autores del Quijote forjan entonces, para Cervantes, los estratos antiguos de la novela: en ellos se concreta la certeza de una geología novelesca" (Balza, Este mar narrativo). El libro que leemos presupone una estirpe previa, precursores sin rastro que sobreviven en la voz de un continuador. Harold Bloom se refirió a la angustia de las influencias para describir el modo en que un escritor lidia con una tradición opresiva y elige los antecedentes que lo determinan. La novela de Cervantes está atravesada por una ilusión de la precedencia, el "licor de los mitos", como escribe 
Balza. No podía ser de otro modo en un personaje que nace como tal con la lectura.

El protagonista de Cervantes quiere ejercer la caballería cuando ha desaparecido del mundo e incluso de las novelas. Por eso su indumentaria es un disfraz. Don Quijote utiliza la habilidad manual que antes empleaba en la confección de jaulas y palillos de dientes para fabricarse armas de cartón. Así, se lanza al camino como tosco remedo de sus modelos, un personaje de carnaval que representa su rol con grotesca exageración. Su identidad se construye con honesta falsía: es deliberadamente artificial.

De acuerdo con Marthe Robert, el acto más radical del Quijote es la imitación: se disfraza para asumir un código preestablecido. Sin embargo, este deseo de mímesis no encaja con el medio en que se mueve: quiere ser lo que no puede ser. Como Pierre Menard, el Caballero de la Triste Figura es original, no por la conducta que se asigna — calcada de otra—, sino por el contexto. La copia es reinventada por la forma en que la miran.

\section{Leer lo que podría ser}

El Quijote propone un decisivo criterio de verosimilitud. Su autor se sitúa fuera de la obra, como mero intercesor, y no confunde la realidad con la invención. En otras palabras: no lee su libro como lo haría don Quijote. La revelación de la identidad de Cide Hamete Benengeli va acompañada de esta descripción: estamos ante una "gravísima, altisonante, dulce e imaginada historia". De los cuatro atributos que definen lo que leemos, el de clausura denota su condición imaginaria. En la segunda parte, el protagonista desciende a la Cueva de Montesinos y atestigua portentos "cuya imposibilidad y grandeza hace que se tenga esta aventura por apócrifa". Máquina desaforada, el Quijote descalifica lo que cuenta, y aun así lo cuenta. El placer del texto deriva, en buena medida, de este ejercicio de disolvencias.

Aire en el aire, la fabulación reclama una legalidad alterna a la del mundo de los hechos. Como ha mostrado Juan José Saer, la ficción no es lo contrario de la verdad; construye una segunda realidad, la de la invención convincente: "Al dar un salto hacia lo inverificable, la ficción multiplica al infinito las posibilidades de tratamiento. No vuelve la espalda a una supuesta realidad objetiva: muy por el contrario, se sumerge en su turbulencia, desdeñando de antemano la actitud ingenua que consiste en saber cómo esa realidad está hecha. No es una claudicación ante tal o cual ética de la 
verdad, sino la búsqueda de una un poco menos rudimentaria" (El concepto de ficción). Tal es el presupuesto que Cervantes sostiene a lo largo del libro: una historia imaginada que sólo don Quijote, en su locura, toma en sentido literal. Cervantes aparta la novela moderna de la verificación realista y hace de la ironía su principio de juicio. Si nos reímos de los dislates es porque podemos distinguir lo real de las figuraciones del caballero andante, pero sobre todo porque podemos atribuirles una lógica. La bacía de un barbero difiere de un yelmo de guerra, pero una disparatada similitud puede unirlos. Don Quijote carece de la distancia irónica que permite vincular distorsionando. Estamos, pues, ante dos niveles de lectura, la literal, practicada por el protagonista, y la que pone en tela de juicio lo que mira, que Cervantes pide a su lector.

Los repetidos descalabros no alteran la opinión del caballero: "Yo sé quién soy", exclama, cuando un campesino trata de devolverlo a la realidad. A propósito de esta escena Sergio Fernández comenta en su Miscelánea de mártires: "Es en este momento cuando del rechazo, o sea de la adversidad, curiosísimamente le nace a don Quijote la convicción del ser, antes afirmado en el amor: 'Yo sé quién soy' le dice, frase contundente porque está plagada de ironía ya que quien la expresa es un hombre inmerso en la ensoñación. ¿Será entonces que sólo en el hechizo un hombre puede decir que sabe lo que es?". La sinrazón del Quijote se funda en creer, sin fisuras, que sabe quién es en un mundo donde todo es mudable y la sensatez aconseja no estar seguro de nada. Lección de escepticismo, el Quijote hace que el juicio pase por el tamiz de la incertidumbre: todo podría ser de otro modo. En este sentido, contraviene refranes tan españoles como "las cosas como son" o "que te lo digo yo". Nada es nunca de manera definitiva y la verdad no deriva de la autoridad que el testigo se confiere a sí mismo.

Don Quijote lee en clave medieval, en busca de gigantes, de lo sobrenatural que no requiere de otra causa que su mera aparición. Una y otra vez, paga un elevado precio por no distinguir persona y personaje, el hecho de la pose; es uno con su lectura y esto lo vuelve gracioso para el lector moderno inventado por Cervantes: el que acepta una historia imaginada, donde lo único creíble es el principio mismo de la invención, el procedimiento, la máquina narrativa.

De acuerdo con Borges, las situaciones en las que Hamlet ve una obra teatral y don Quijote lee el Quijote revelan que "si los caracteres de una ficción pueden ser lectores o espectadores, nosotros, sus lectores o espectadores, podemos ser ficticios". La fuerza de esta postulación fantástica deriva de una inquietud que suele acompañar el acto de leer: de pronto, 
el universo convocado por las letras adquiere mayor dosis de realidad que la circunstancia en que ejercemos la lectura. Esta repentina suplantación en la conciencia es similar a la del sueño o los falsos recuerdos que damos por reales. El lector del Quijote sabe que no puede creer en las páginas como lo haría Alonso Quijano; al mismo tiempo, la continua puesta en duda de lo que atestigua lo lleva a dudar de sí mismo. La construcción del sujeto escindido que determina la novela del siglo XX proviene de Cervantes no tanto por los personajes que pueblan su obra sino por el personaje que pide que la lea. $\mathrm{Al}$ iniciar sus cursos de literatura, Nabokov comentaba que el máximo personaje que puede concebir un autor es otro tipo de lector. Don Quijote sale a La Mancha para inventar a sus lectores.

En su novela El árbol de Sausurre, Héctor Libertella llama la atención sobre un accidente semiótico: la palabra "yo", decisiva para todo relato, reúne en español dos conjunciones opuestas (y/o), la unión y la disyuntiva, lo que articula y lo que disgrega. El fragmentado "yo" contemporáneo es fiel a ese oráculo gramatical, el tejido de adhesiones y disonancias con que leemos el Quijote.

\section{Tiempo cero, los polos opuestos}

Desde el punto de vista de la historia de la lectura, la novela de Cervantes se funda en un gesto extemporáneo. La tradición de la caballería andante ya ha desaparecido y don Quijote se ve obligado a buscar las armas de sus bisabuelos. Sus claves de referencia, el Amadís de Gaula o Tirant lo Blanc, son obras del pasado. A cada nuevo encuentro debe explicar lo que su extravagante indumentaria representa (tantas veces lo hace que, de pronto, al repetir que su descanso es pelear, dice: "etcétera"). La caballería no es un valor entendido en los campos que recorre. En un giro típico de su carácter, Sancho piensa que los extraños no los comprenden por ignorancia, madre de todas las perplejidades. Cuando una moza no sabe lo que significa ser "caballero aventurero" la considera demasiado nueva en el mundo (en realidad, debería ser viejísima para discernir a un caballero andante a golpe de vista).

Para Ricardo Piglia, la novela de Cervantes es la puesta en escena de un lector extremo: "Hay un anacronismo esencial en don Quijote que define su modo de leer. $\mathrm{Y}$ a la vez surge de la distorsión de esa lectura. Es el que llega tarde, el último caballero andante. En la carrera de la filosofía gana el que puede correr más despacio. O aquel que llega último a la 
meta, escribió Wittgenstein. El último lector responde implícitamente a ese programa".

El tema de perpetuar o destruir una forma de leer aparece en el capítulo VI a propósito de la conveniencia de salvar libros o quemarlos, y es retomado en pasajes paródicos donde Cervantes demuestra cómo se leería esa página escrita con la retórica, ya gastada por el tiempo, que apostaba a imágenes codificadas, donde el sol extendía su rubia cabellera. En forma propositiva, Cervantes escribe fuera de la costumbre; su protagonista perpetúa un género a cuyas reglas él no se sujeta como autor. Al referirse a Tirant lo Blanc, hace que el Cura encomie la cuota de realidad de la que carecen otras novelas de caballería: "aquí comen los caballeros, y duermen y mueren en sus camas, y hacen testamento antes de su muerte". Don Quijote es devorado por la ficción pero actúa en un entorno donde aspira las emanaciones corporales de su escudero. Muy pronto descubre que las dosis de realidad de Tirant lo Blanc no bastan para narrar esa imaginada historia. El primer signo de discrepancia entre lo que ha leído en las novelas de caballerías y la sociedad que lo circunda tiene que ver, de manera significativa, con el dinero. En el capítulo III, un ventero le pide que pague y él informa que va "sin blanca", como todos los de su linaje. El ventero advierte que su interlocutor sólo entiende razones literarias y le informa que en los relatos de caballería no mencionaban el dinero por simple pudor, pero que se trataba de un trato implícito. A partir de ese momento, la economía de la novela pasa de la edad media al Renacimiento: el dinero hará circular más acciones que los gigantes. Don Quijote paga, franqueando con su peaje el cruce de lo fantástico a lo real.

Cervantes establece una peculiar tensión entre los portentos ópticos que su protagonista atestigua y las muy reales pedradas que recibe. El viaje de ida y vuelta entre fabulación y realidad depende de los diálogos entre el caballero andante y su escudero. En el capítulo IX se informa que Sancho no sabe leer; la oposición de criterios no puede ser más radical. Don Quijote asume el mundo como novela ante un testigo iletrado. Dos tradiciones se enfrentan en los diálogos que van del caballo al burro: la literaria y la oral, el sentido figurado y la comunicación pragmática. "El Quijote es único y Sancho es todos los demás", observa Rodrigo Fresán. Esta diferencia marca dos estilos, el irrepetible del caballero andante y el saber común del escudero. La novela es la zona donde ambos discursos se cruzan y contaminan: don Quijote alcanza la sensatez argumental en situaciones creadas por su delirio y Sancho se finge loco por instinto de supervivencia. La inversión 
kafkiana, proseguida por Borges, de que es Sancho quien crea a don Quijote, tiene su origen en la propia novela de Cervantes. El escudero bautiza a su amo como Caballero de la Triste Figura y así define su condición melancólica. Don Quijote acepta la iniciativa de su subordinado, pero la atempera considerando que no se le ha ocurrido a él: el sabio árabe que compone la obra le puso esa idea "en la lengua y en el pensamiento". Si Sancho "escribe" al Quijote es porque ya está escrito de antemano. Kafka suprime la última vuelta de tuerca y preserva la autoría de Sancho.

Lo decisivo en este teatro de atribuciones son las líneas de fuerza entre dos campos opuestos, la necesidad de choque. La dinámica requiere de otra demarcación invisible, el "justo medio" entre el Quijote y Sancho, entre la ensoñación y la rusticidad, una línea intangible y necesaria, una frontera intermedia, donde la fantasía y el sentido común se benefician recíprocamente.

¿Qué sería de la novela sin sus polos opuestos? Cuando don Quijote se harta de ser juzgado y prohíbe a Sancho que hable mientras avanzan por la Sierra Morena, la trama se hace imposible. El escudero guarda un silencio rabioso, convencido de que las cosas que no se dicen se pudren en el estómago. El caballero levanta el castigo, resignado a que su acompañante lo valore como un espejo oponente, es decir, resignado a que lo narre.

Las historias contadas por Sancho tienen la impericia de quien ignora la síntesis y procura que la trama sea igual a la vida. Su amo le llama la atención de que todo lo dice dos veces y él da una prueba patafísica del verismo como asiento de la narración. Refiere que un pastor cruzó trescientas cabras por el río Guadiana y le pide a su escucha que esté atento al número de cabras que van cruzando; cuando don Quijote pierde la cuenta, Sancho pierde el hilo del relato.

Novela-biblioteca, el Quijote incluye narraciones ajenas y traspasa con libertad sus límites territoriales. Las novelas intercaladas suelen irritar o entusiasmar a los lectores extremos del libro. En todo caso, la idea de interrupción es esencial al acto de leer y no podía estar ausente de la desmesurada vida del lector don Quijote.

¿Es posible hablar de un lector perfecto de la novela? A propósito del Finnegans Wake, escribe Piglia: “Joyce llega más lejos que nadie en la ilusión de escribir con una lengua propia ... El escritor pone al lector en el lugar del narrador. Un lector inspirado que sabe más que el narrador y que es capaz de descifrar todos los sentidos, un lector perfecto". Cervantes no concibe una lengua privada, pero crea una forma nueva: es el primer lector 
de una historia que cancela una tradición y funda otra, un lector temperamental e improvisado, algo ya imposible en un mundo cervantino. La posteridad ha perfeccionado la manera de leer de la que Cervantes fue el primer aprendiz.

Seguramente, el autor se asombraría de las lecturas que permiten la vigencia de su obra. Don Quijote tiene cincuenta años, edad que se puede padecer sin excesivo daño en la actualidad. Sin embargo, la fuerza de representación del libro y de la iconografía que lo ha acompañado durante cuatro siglos remiten a lo que significaba cumplir cincuenta años en el Siglo de Oro. Al leer el libro imaginamos las desmesuras de un anciano. El Caballero de la Triste Figura sabe por Sancho que un diente vale más que un diamante y él ha perdido demasiados para ser ajeno a su deterioro. En lo que toca a su indeleble aspecto físico, don Quijote es leído como lo fue en su día; en cambio, ciertas escenas se han expandido con una fuerza virtual que las hace ocupar mucho mayor espacio en el repertorio de la cultura del que tienen en el texto. Es el caso del embate a los molinos de viento. Una página y media de la obra se han convertido en su símbolo absoluto y más extendido, como si las aspas de los molinos centrifugaran una energía de representación.

\section{Escritura y movimiento}

De acuerdo con Hemingway, la literatura norteamericana comienza cuando Mark Twain escribe: "es hora de irnos a aquellas tierras". Una invitación al viaje. Se trata, sin duda, de un gesto cervantino: salir al mundo en busca de experiencia, estructurar la trama a partir de los desplazamientos.

Hemingway podría haber encontrado en Twain otros sesgos cervantinos (Huckleberry Finn alude al antecedente de Tom Sawyer - un libro como reflejo de otro- y narra a partir de dos protagonistas contrastados), pero eligió un gesto vinculado a la errancia. "Es hora de irnos a aquellas tierras", la frase atañe al espacio pero también al tiempo, el imperioso instante de partir. Para situar a su personaje en su primera salida, Cervantes escribe: "Una mañana, antes del día", la hora fronteriza en que ya comenzó una fecha pero la luz aún no la acompaña. Cruzar es la consigna.

De manera sintomática, don Quijote se sirve de una metáfora espacial para que Sancho entienda el carácter de sus aventuras: no son de ínsulas sino de encrucijadas. Aunque se refiere a la pretensión del escudero de hacerse de una ínsula en recompensa a sus fatigas, el protagonista con- 
trasta dos morales respecto al territorio: la posesión aislada, la isla, o la zona de encuentro y cruce, la frontera.

La tensión entre los anhelos sedentarios de Sancho y el impulso errante de su amo se ponen de manifiesto cada vez que escogen lugar para dormir. El escudero desea los muros protectores de una venta; don Quijote, en cambio, privilegia la intemperie; dormir a cielo descubierto le parece un "acto posesivo" que facilita "la prueba de su caballería", una apropiación pionera de la tierra de nadie. La imagen canónica de la narrativa del far west, el vaquero que duerme junto a la fogata usando como almohada su silla de montar, se desprende de este gesto de caballería.

Las fronteras son formas provisionales de definir la identidad; se es de un sitio en oposición a otro. En un sentido político, la frontera es una advertencia, una línea del peligro. Sólo hay algo más arriesgado que cruzarla en forma ilícita: mantenerse en esa zona de indefinición, ser la indocumentada presa de la patrulla fronteriza. En el plano psicológico, esa es la condición de los borderliners. El síntoma difícilmente se aplica a don Quijote. Su mente no deja de transgredir límites; pasa del delirio a la sensatez en forma contundente: es un migrante sin tregua, no alguien que vive en borroso estado fronterizo.

Pocos recursos resultan tan efectivos para desestabilizar una norma como el sentido del humor. No es casual que en los aeropuertos estadounidenses un letrero anuncie que están prohibidos los chistes, ni que el Quijote se sirva de la comicidad para saltar de la realidad a la invención. En una aduana, el escritor viajero B. Traven repitió la aseveración del caballero andante: “¿Para qué necesito pasaporte? Yo sé quién soy”. Pero la frontera es la línea donde la identidad vale menos que su representación.

Otros célebres usuarios del humor como recurso de contrabando, los hermanos Marx, situaron uno de sus gags en una frontera. Al desembarcar en Nueva York, Groucho presenta el pasaporte de Maurice Chavalier. "Usted no se parece a Maurice Chavalier", le dice el guardia. Groucho canta para mostrar su parecido.

\section{De Rocinante al Impala: caballeros y detectives}

En un ensayo sobre lo quijotesco como virus, escribe Rodrigo Fresán: "El Quijote es una línea flaca pero fuerte, un límite definitorio y definitivo, una frontera que una vez cruzada no ofrece pasaje ni paisaje de vuelta: de un lado queda la gloriosa tradición de la literatura de caballería y hazaña 
pura, del otro surgen los efectos de esa literatura - de esas ficcionessobre los territorios de la realidad. Y el Quijote y lo quijotesco -implacables - se las arreglan para funcionar como funcionan las vacunas: atacan al virus con el virus (recordar que finalmente don Quijote es vencido por una escenificación terapéutica de su propia locura: el bachiller Sansón Carrasco disfrazado como el Caballero de la Blanca Luna, quien antes fue el Caballero de los Espejos) pero, en lugar de neutralizarlo, lo potencian convirtiéndolo en otra cosa, en algo novedoso por entonces, en algo que sigue siendo original". Fresán encuentra el nacimiento de un género en el argumento que atrapa al protagonista con su propio delirio. La novela nace con el sello de la metaficción; desde su origen, se lee a sí misma.

Cuando a Barry Gifford le preguntaron acerca de la evidente influencia de En el camino, de Jack Kerouac, en su obra Corazón salvaje, respondió que todas las road novels provenían del Quijote. Cervantes funda por partida doble la novela moderna y el subgénero de la novela nómada que llega hasta Los detectives salvajes, de Roberto Bolaño, donde Ulises Lima y Arturo Belano, aprendices de poetas, viajan en sentido inverso a don Quijote: no buscan que la vida compruebe lo que leyeron en los libros; viven para investigar la materia que puede ser literatura. A bordo de un Impala, recorren el norte de México rumbo a la zona de indefinición, lo híbrido, la frontera tex-mex. Como ocurre con las cabalgaduras del Quijote, el desvencijado coche de los poetas potencia las incertidumbres de la trama. Thelma $\&$ Louise, la película de Ridley Scott, representa una versión exacerbada del tema, con una pareja de mujeres por protagonistas: la errancia se transforma en fuga y el último cruce es un salto al abismo, única opción de no volver a la restrictiva realidad.

Don Quijote es un lector metido a hombre de acción. Su doble papel se expresa con nitidez en el discurso sobre las armas y las letras, donde Cervantes se despoja con holgura de su juego de suplantaciones y habla por sí mismo en boca de don Quijote. El escritor soldado lamenta la triste recompensa que reciben quienes ponen su vida en prenda y lo difícil que resulta probar la valentía personal en una era que cuenta con "endemoniados instrumentos de artillería". El lance solitario del caballero que obra por convicción propia es ya imposible.

Varios siglos después, el detective establece en la cultura popular una sugerente mediación entre las conjeturas sobre la realidad y la acción. A propósito de Poe escribe Piglia: "En Dupin, en la figura nueva del detective privado, aparece condensada y ficcionalizada la historia del paso del 
hombre de letras al intelectual comprometido. En muchos sentidos, el detective permite plantear un debate sobre el letrado y está ligado a la clásica discusión entre autonomía y compromiso. Para decirlo mejor, el detective plantea la tensión y el pasaje entre el hombre de letras y el hombre de acción". Cervantes sabe que el guerrero individual puede poco ante la "maldita máquina" de la pólvora; al postularse como "profesor de las armas" en esa época infausta, don Quijote realza los peligros que corre y asume el deber de razonarlos. El discurso tiene por fin último mostrar los mayores riesgos y las exiguas recompensas que aquejan al "mílite guerrero"; sin embargo, es lanzado por un lector absoluto, que vive la vida como un libro. El detective aparece como una figura donde cristalizan el afán de leer el mundo (las huellas dactilares en la escena del crimen) y el deseo de enfrentar los desafíos de la acción; por eso para Piglia este investigador armado es una variante popular del intelectual comprometido. Los detectives salvajes de Roberto Bolaño prosiguen esta serie: poetas interesados en indagar la vida para transformarla, representan una variante intuitiva y lúdica del intelectual comprometido. La insistencia de Bolaño en la valentía como principio ético y estético encuentra en el discurso sobre las armas y las letras su causa remota.

\section{La frontera melancólica}

Para don Quijote la valentía es una escala de percepción: Sancho no ve lo mismo que él porque tiene miedo y eso turba sus sentidos. En cambio, en su intrepidez, él ve de más aunque no siempre lo advierta. Ante un rebaño de ovejas concibe un batallón integrado por gente de muy diversas procedencias: "aquí están los que bebían las felices aguas del famoso Janto . . los que beben las corrientes cristalinas del olivífero Betis; los que tersan y pulen sus rostros con el licor del siempre rico y dorado Tajo; los que gozan de las aguas del divino Genil; los que pisan los tartesios campos, de pastos abundantes; los que se alegran en los elíseos jerezanos prados...". La descripción de la otredad, conformada la patrulla fronteriza, incluye paisajes: ríos, campos, zonas de cruce. Animado por la valentía y el deseo de unir imaginación y acontecimientos, don Quijote sobreinterpreta un rebaño como una mezcla de culturas. Los desaguisados — las palizas que lo regresan a sí mismo - revelan otro rasgo de su carácter, la melancolía, diagnosticada por Sancho desde el comienzo del libro. No se trata de una mera tristeza, sino de una condición sensible que debilita el cuerpo al tiempo que despierta otras facultades. 
Roger Bartra ha estudiado en detalle el peso cultural de la melancolía, de la edad media a La náusea, de Jean-Paul Sartre, cuyo primer título fue Melancholia. En la tradición española, un antecedente esencial en el estudio del tema es el Libro de la melancolía, publicado en 1585 por Andrés Velásquez, médico de Arcos de la Frontera. De acuerdo con Bartra, el lugar de nacimiento de Velásquez prefigura su interés por el humor melancólico: "Me parece que una de las claves que nos permite vislumbrar la gran importancia del problema abordado por Andrés Velásquez en su libro la podemos hallar en el nombre mismo de la ciudad donde fue escrito. La melancolía era un mal de frontera, una enfermedad de la transición y del trastocamiento. Una enfermedad de pueblos desplazados, de migrantes, asociada a la vida frágil de la gente que ha sufrido conversiones forzadas y ha enfrentado la amenaza de grandes reformas y mutaciones de los principios religiosos y morales que los orientaban" (Cultura y melancolía). El Quijote pone en escena la gran enfermedad del desplazamiento. Nada más lógico que un personaje que confunde la realidad y el deseo, escrito por un árabe transterrado a la Mancha y que entra en los libros por el ensamblaje de un padre postizo, tenga como estrella el negro sol de la melancolía. Para Bartra, la melancolía quijotesca es ambivalente: provoca la locura del protagonista, pero también le confiere su extraña lucidez contra la norma: "El Quijote está inmerso en una nueva textura intelectual que reivindica el carácter positivo aunque riesgoso del humor negro". También en su psicología, el protagonista asume una estrategia del disfraz. Émulo de Amadís, copia su melancolía y alcanza así una tristeza artificial: "la dificultad de explicar la melancolía de don Quijote proviene de que está inscrita en un simulacro".

No hay duda de que el protagonista de Cervantes ha enloquecido por las lecturas; sin embargo, dentro de su delirio es capaz de representar teatralmente la locura para aproximarse a sus modelos ficticios; es en esta melancolía fingida donde el personaje se divierte más y reflexiona con repentina sensatez. En el capítulo XLIV de la segunda parte, ya adiestrado en el repertorio de sus reacciones, el Caballero de la Triste Figura manipula su melancolía ante una duquesa para adoptar una conducta a un tiempo seductora y casta: se hace el interesante al sugerir que su tristeza tiene un origen difícil de expresar; al mismo tiempo, esta pesadumbre le da un pretexto para no ser atendido por las doncellas dispuestas a desnudarlo. La melancolía es aquí impostura, estratagema.

Para Bartra, el engaño que practica don Quijote se inscribe en los juegos cortesanos de la época y revela el alcance más profundo de su 
malestar, la forma en que "la melancolía artificial puede curar la melancolía real". Remedio para melancólicos, el Quijote participa de la simulación como ejemplo y terapia. El protagonista experimenta el mal en las dos zonas que determinan la novela, la realidad y la fantasía; en ocasiones su melancolía es genuina, en otras fingida. Nunca don Quijote es tan libre como cuando sabe que es falso ni tan cuerdo como cuando en forma deliberada se representa a sí mismo. La realidad —el contexto-, que no entiende de representaciones, espanta sus humos escénicos para devolverlo al entorno donde sólo es un loco.

Fresán se ha preguntado por qué los manicomios de las comedias están llenos de Napoleones pero no de Quijotes. ¿No sería emblemático tener en esa galería al loco por antonomasia? El autor de Jardines de Kensington da con una sugerente respuesta: "Para creerse Quijote hay que ser Quijote. Y hay que estar siempre afuera y nunca entre los desquiciados. En este sentido - y a la hora de la patología manicomial — un Quijote encerrado no tiene sentido alguno. No tiene razón de ser". Criatura virtual, el Quijote carece de sentido si vuelve en sí, del mismo modo en que carece de sentido si todos comparten sus locuras o si comparece en un manicomio como loco "legítimo". Su energía depende de no realizarse del todo; es lo que existe como posibilidad, ambigüedad, frontera, realidad intangible.

A pesar de sus continuas derrotas y de su muerte, que ratifica el poderoso veneno de las novelas de caballerías, don Quijote eleva el humor melancólico a una variante de la sensatez a contrapelo, la feraz "tristeza del mundo" que encontraría otros mensajeros en Goethe, Nietzsche, Benjamin y Sartre.

Simulacro de simulacros, don Quijote muere para que no vuelva a ser imitado y deja por testamento la segunda y definitiva parte del libro. Cide Hamete Benengeli, que sólo ha existido para esta obra, se expresa al final a través de la pluma que está a punto de colgar para siempre: "para mí sola nació don Quijote, y yo para él; él supo obrar, y yo escribir". Miguel de Cervantes es quien pone las comillas. El padrastro hace lo suyo.

Cervantes narra desde los linderos del texto; sugiere que se lea con atención determinado pasaje, anuncia que otro se explicará más tarde, matiza la fuerza de los portentos. El narrador que se discute a sí mismo depende de la noción de umbral, de límite transgredido para estructurar su narración. Sancho pierde el hilo de su historia porque las cabras no terminan de cruzar el río Guadiana. Cruzar lo es todo. Hora de irnos a esas tierras.

Ningún final más cervantino que éste: "y alzando los ojos vio lo que se dirá en el siguiente capítulo". El protagonista observa lo que será narra- 
do; el libro se construye al ser leído. Cervantes abre una pausa entre dos capítulos, el XXI y el XXII. Don Quijote alza la vista: al otro lado, su historia continúa. Al cruce de esa frontera, a su traslado cumplido, debemos una curiosa actividad: la literatura moderna. 